\title{
Application of Rapid Prototyping Technology to Improve Spatial Visualization
}

\author{
Jason T. Czapka, Manssour H. Moeinzadeh, James M. Leake \\ Department of General Engineering \\ University of Illinois at Urbana-Champaign
}

\begin{abstract}
This paper describes spatial visualization experiments conducted at the University of Illinois Urbana-Champaign. The investigation's focus was the use of physical models, made using rapid prototyping technology, to improve spatial visualization skills in an introductory engineering graphics course.

Two studies were conducted. In the first study students enrolled in experimental lab sections had the benefit of physical models, fifty in all, of varying levels of difficulty, as an aid to visualization while engaged in the study of orthographic projections. The associated control group used traditional teaching methods, without the benefit of the physical models.

The second study was designed specifically to help students identified as having poor visualization skills. The Purdue Spatial Visualization Test: Rotations (PSVT:R) was used as both a pre and post-test for all students enrolled in the graphics course. The PSVT:R pre-test results were used to select students for the second study. Half of the students identified as having scored poorly on the PSVT:R were invited to a workshop on orthographic projection. The workshop employed additional rapid prototyping models, fourteen in all, as both haptic and visual aids, in conjunction with pencil and paper exercises. The workshop attendees were the experimental group, whereas the non-attendees were the control group.
\end{abstract}

Two metrics were used to evaluate the effectiveness of the physical models. The first metric was the improvement in PSVT:R scores from pre to post-test. The percentage of improvement was greater for the experimental group in both studies. This suggests that the use of physical models helps students to improve their visualization skills to a greater extent than with traditional teaching methods alone.

As a second metric, scores from the sketching segment of an engineering graphics exam were used (the exam is a course requirement). The sketching segment of the exam consisted of auxiliary, missing, and section view problems. For the second study the experimental group had higher scores than the control group on the sketching segment of the exam. Thus the workshop group showed improvement in class performance as well as in visualization skills. Increased scores on this segment were not realized for the experimental group in the primary study, however. Thus the workshop option proved more beneficial than the in-class experiment, although positive feedback was received from students and instructors alike for both experiments. 


\section{Introduction}

Visualization studies over the past century have proven to be a vital tool for teaching engineering graphics. With recent advancements and cost reductions in rapid prototyping technology, comparatively inexpensive, highly detailed physical models can be made and used as visualization aids. This study presents the results of spatial visualization experiments conducted at the University of Illinois Urbana-Champaign (UIUC). The investigation's focus was the use of physical models, made using rapid prototyping technology, to improve spatial visualization skills in an introductory engineering graphics course.

The study occurred within a three-hour credit service course entitled Engineering Graphics and Design (GE103) taught in the Department of General Engineering at UIUC. In GE103 emphasis is placed on computer modeling (using both AutoCAD and Autodesk Inventor) and freehand sketching. On average, there are 275 students enrolled in the course, which is offered in both the fall and spring semesters. This research was based upon results obtained in the Fall 2001 semester, during which 298 students completed the course. There were 18 separate sections, each with from 14 to 18 students.

The basic course structure entails five contact hours per week. There are two, one-hour lectures each week taught by one of the paper's authors. There is also a weekly, two-hour computermodeling lab run by a teaching assistant with the help of two undergraduate lab assistants (during which two sections are present). Finally, there is a weekly, one-hour sketching lab run by a teaching assistant (during which one section is present). The primary study described in this report was conducted in the sketching lab. Assessment in GE103 includes online and sketching quizzes, modeling and sketching homework, modeling and written/sketching exams, and a group design project.

Most engineering graphics educators believe that physical models are beneficial to their students when used properly, typically after the student attempts and falters on an assignment. Yet very few engineering graphics programs seem to place an emphasis on such aids. Whiteacre ${ }^{[1]}$ stated that he prefers to have physical models for each student, but found that the cost and manufacture of models made it impractical. Rapid prototyping technology alleviates these issues, since it allows for the mass manufacture of inexpensive models. The Department of General Engineering at UIUC purchased a three-dimensional (3-D) printer in the summer of 2000 and has since utilized the machine in a variety of courses. These courses include senior design, product development, and introductory robotics, as well as GE103. As this technology becomes increasingly accessible, the argument for additional physical model usage becomes more reasonable.

\section{Use of Physical Models in Engineering Graphics}

Several investigators (Miller ${ }^{[2]}$, Vander Wall ${ }^{[3]}$, Rowe ${ }^{[4]}$, Orth ${ }^{[5]}$, and DeJong ${ }^{[6]}$ ) sought to increase understanding of spatial ability development and learning styles in engineering graphics courses by using physical models to improve visualization skills. The real models in Miller's study consisted of twenty-five wooden blocks, with each student (sixteen total) receiving one set. The work was in part based on the educational premise that there are different kinds of learners, 
including visual and haptic. Visual learners learn through the modality of sight. Consequently visual learners normally perform adequately given traditional engineering graphics instruction, which includes overhead projections, chalkboard drawings, and printouts. Haptic learners learn through the modality of touch. However, the majority of engineering graphics classes do not provide stimulus in this modality. The addition of physical models would add/increase this stimulus in these courses, and could do so in many other engineering courses as well, thus benefiting haptic learners.

Miller's study attempted to identify visual and haptic learners, and then to test the effectiveness of real and computer generated models, as well as traditional teaching, in enhancing visualization abilities. Improvement was measured with the Mental Rotations Test (MRT) (Vandenberg ${ }^{[7]}$ ). Results from the MRT indicated that visual learners had greater spatial abilities than haptic learners. However, all three teaching approaches were deemed equally effective for either visual or haptic learners, based on insignificant differences in MRT results. Nonetheless, the results from Miller's student questionnaire provided support for the addition of real and computer generated models to the traditional curriculum.

In another study, Vander Wall used insulation foam board models as teaching aids in engineering graphics classrooms. He qualitatively concluded that increased usage of physical models would improve students' ability to visualize objects and understand the material. He also felt that the class time saved and understanding gained while using physical models was more than worth the effort required to create the models. However, it should be noted that spatial ability was not measured quantitatively.

Rowe also felt that physical models were useful in the classroom. However, his descriptive geometry study did not provide models for each student, nor did it attempt to measure improvement in any way. Additionally, Orth believed in the benefits of physical models only in special cases where the student could not progress without them. Like Rowe, this research did not provide each student with models, nor did it attempt to quantitatively measure any benefit from classroom demonstration models.

\section{Rapid Prototyping Technology}

3-D printing is a subset of rapid prototyping that is affordable, quick, size constrained, and safe to use in an office environment. As compared with rapid prototyping machines that can cost as much as $\$ 500,000$, a 3-D printer can be attained for about $\$ 50,000$. Typical part build times for 3 -D printers are generally less than those produced using the more expensive rapid prototyping technology. The build volume for 3-D printers is typically around 10" x 10" x 10", which is significantly smaller than that of many rapid prototyping machines. This is partly due to size limitations of the 3-D printing unit, which often takes up an allotment of floor space comparable to that of a large two-dimensional (2-D) printer. Since 3-D printers are designed to operate in an office environment, in addition to a small footprint, they typically put out a tolerable decibel level and do not give off hazardous emissions (either chemical or laser). A dedicated operator or machinist is not required to produce quality prototypes with a 3-D printer. Any individual who can create a 3-D computer-aided drawing (CAD) model and use a 2-D printer can run a 3-D printer with minimal training, something not true of all rapid prototyping machines. 
The specific 3-D printer used in this study was the Genisys XS from Stratasys, Inc. (Figure 1). The material used by the Genisys XS is a proprietary polyester produced by Stratasys. It costs about $\$ 100-\$ 140$ per pound. Over 1200 models were made for this study during the course of the semester at an average price of around $\$ 1.50$ per model (material cost only). The average time to build a model was 25 minutes. This represents considerable savings per model when compared to obtaining identically shaped models from a machine shop.

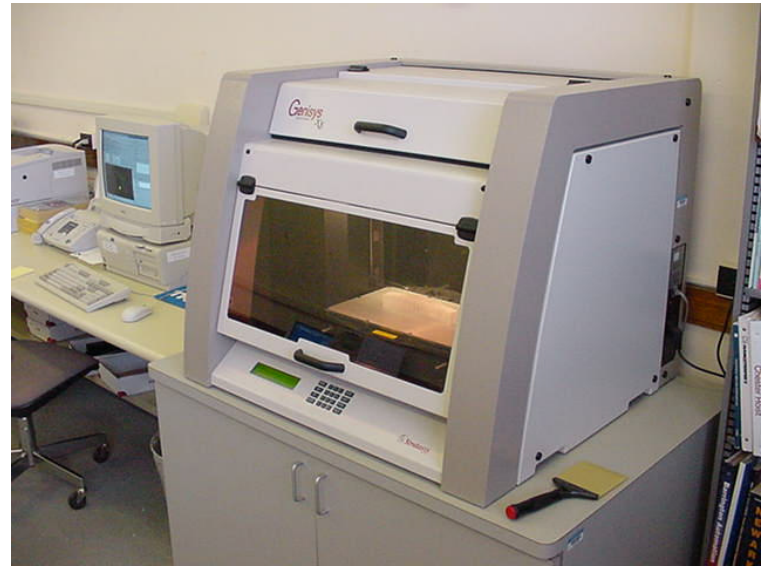

Figure 1: Genisys XS

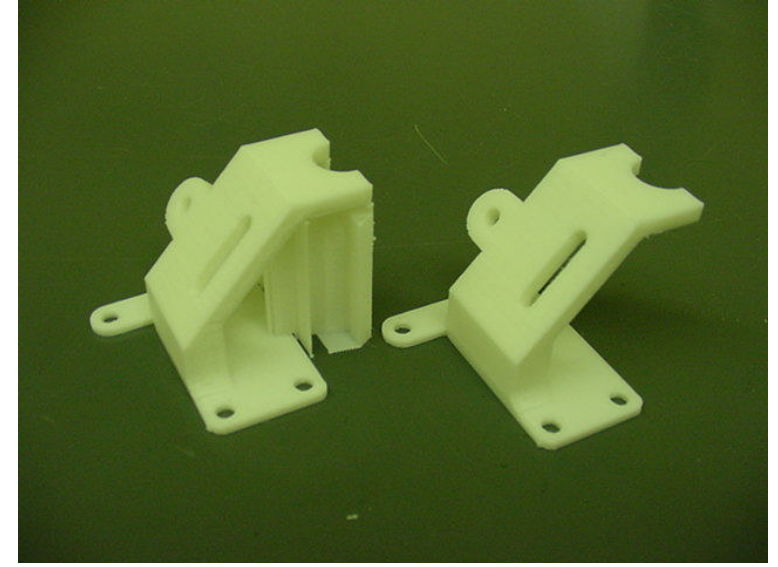

Figure 2: Support Structure Example

The Genisys XS is capable of building models up to a volume of 12 X 8 X 8 inches. It la ys out plastic (polyester resin) at a rate of 4" per second. Accuracy is held to within $+/-0.013$ inches. Positional accuracy is held to $+/-0.001$ inches. The overall dimensions of the unit are $36 \mathrm{X} 32 \mathrm{X}$ 29 inches. The Genisys XS uses AutoGen software as an interface, running on the Windows platform. To create a prototype one must first save a solid model as a stereolithography (STL) file, a simple file format consisting of a closed, faceted geometry of the part. After orienting the part to optimize the build process, AutoGen slices the STL file into many thin layers, which are built one upon the other starting on the build platform. All prototypes are white when removed from the machine. Completed parts are strong (with respect to parts produced with other 3-D printers) and are ready to be sanded, painted, or machined right out of the printer. No sanding, painting, or machining was necessary for the purposes of this study, only the removal of support structure (done by hand, typically without instruments). Support structure is created within AutoGen and built by the Genisys XS automatically where necessary (e.g., to support overhangs). An example of two identical models, one with support structure and one without it, is shown in Figure 2.

The use of rapid prototyping technology in the engineering graphics classroom is not new. To date various schools have used this technology to produce models of design projects and modeling assignments (Kelley, et. al. ${ }^{[8]}$ ). During the Fall 2001 semester, both part and assembly models made with the Genisys printer were used in GE103 lectures. The models were circulated in class and proved to be quite popular. To the best of the authors' knowledge, the literature has not shown an example of rapid prototyping models being used on a per student basis. 


\section{Experimental Design}

This study included two experiments. The primary (in-class) experiment consisted of a control group of 33 students and an experimental group of 35 students. Each group was made up of two sketching sections. The same instructor, one of the authors of this paper, conducted both the experimental and control sections. The experimental group was given rapid prototypes of every sketching assignment object for use in the completion of all relevant assignments. An example of these scale models, from the auxiliary view homework set, is provided in Figure 3. This allowed the students to place the models on their assigned worksheets in various orientations to check their work, or to assist in arriving at the correct solution. This usage is depicted in Figure 4 for a missing/auxiliary view assignment. Further, the experimental group was also provided with rapid prototypes of all relevant objects used in the modeling lab at the outset of the assignment. Examples of some of these models are shown in Figures 5 and 6 (for AutoCAD 2000 and Autodesk Inventor 4.0 respectively). The modeling objects ranged from parts to assemblies, and could be physically manipulated to agree with the orientation of the model as depicted on the computer monitor. An example using the model in this fashion is shown in Figure 7. For both the sketching and the modeling labs, students were only allowed access to these models during class time, or during office hours. The control group, conversely, was not provided with rapid prototypes of any kind.

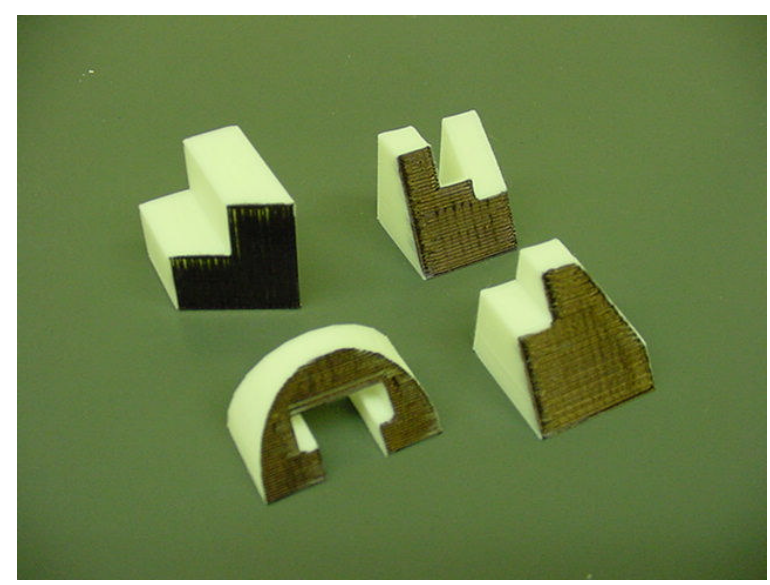

Figure 3: Auxiliary Sketching Objects

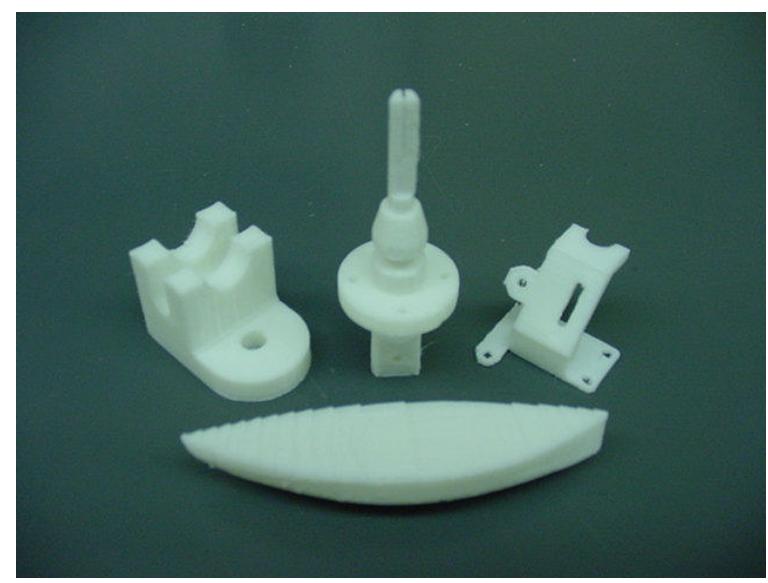

Figure 5: AutoCAD 2000 Modeling Objects

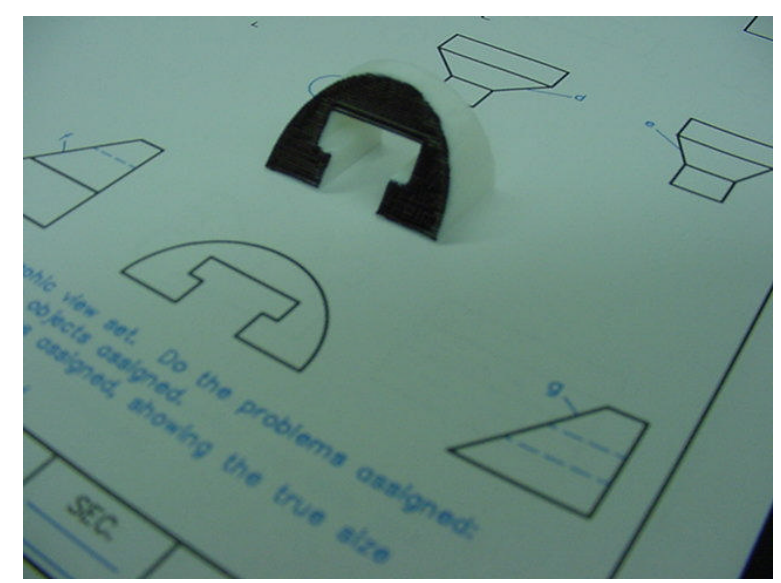

Figure 4: Auxiliary Sketching Object Usage

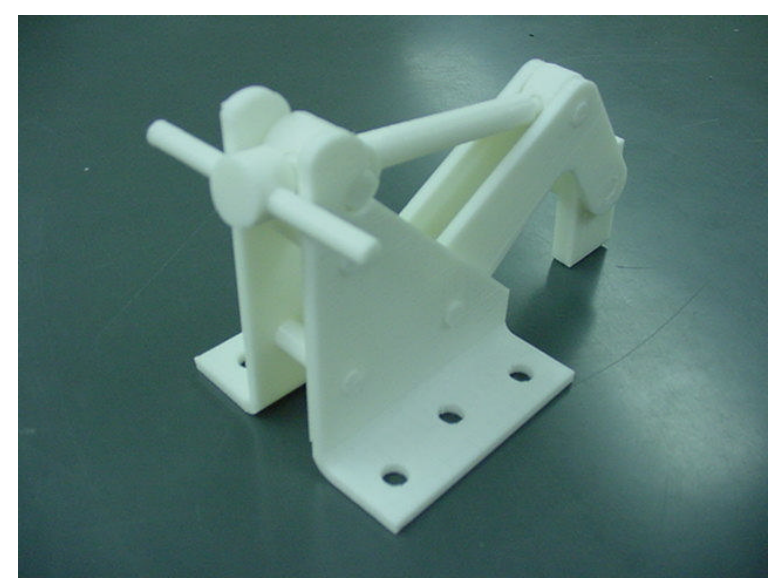

Figure 6: Autodesk Inventor Modeling Objects

Proceedings of the 2002 American Society for Engineering Education Annual Conference \& Exposition Copyright (C) 2002, American Society for Engineering Education 
All GE103 students were required to take an online version of the Purdue Spatial Visualization Test: Rotations (PSVT:R) (Guay ${ }^{[9]}$ ) twice during the Fall 2001 semester; once as a pre-test in the first week of the semester and again as a post-test in the last week of the semester. The PSVT:R is a visualization instrument that consists of thirty multiple-choice questions involving the rotation of various objects. Participants are allowed a maximum of 20 minutes to complete the test. A score of less than 60 percent is considered failing. One caveat regarding the online version is that it is unmonitored. Since both the experimental and control groups, as well as the rest of the GE103 population, took the PSVT:R pre-test, this allowed for a comparison of the mean and standard deviation of the experimental and control groups to the overall class to determine if they fairly represent the population. The course mean was 24.32 with a standard deviation of 2.95. The experimental group had a mean of 23.54 with a standard deviation of 4.88. Similarly, the control group had a mean of 25.26 with a standard deviation of 4.14. This being said, data from the experimental and control groups was considered representative of the population and valid for the purposes of this experiment.

An additional performance measure came in the form of the sketching segment of the second written exam for GE103. This segment was chosen because it requires the use of more visualization skills than any other of the course requirements (except the PSVT:R). This exam is worth 15 percent of each student's final course grade. The exam is structured as follows: 50 percent multiple-choice questions and 50 percent freehand sketching questions (composed of one auxiliary view, two section views, and two missing view problems).

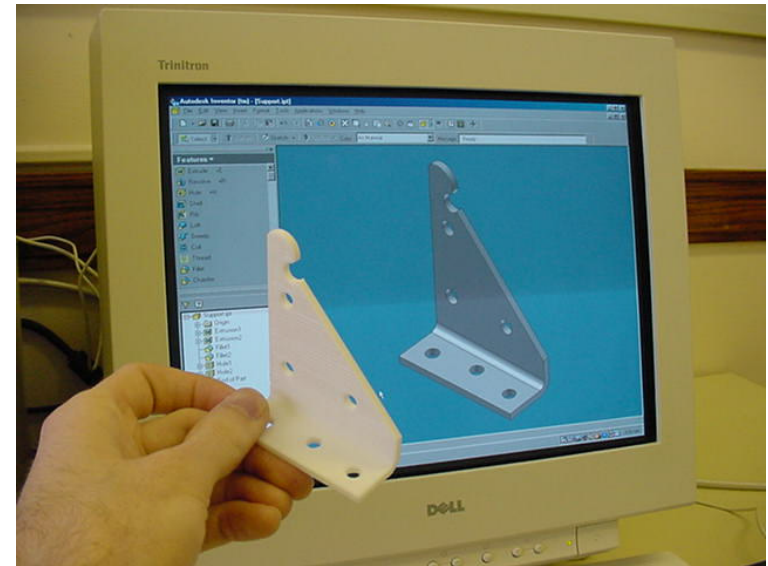

Figure 7: Modeling Object Usage

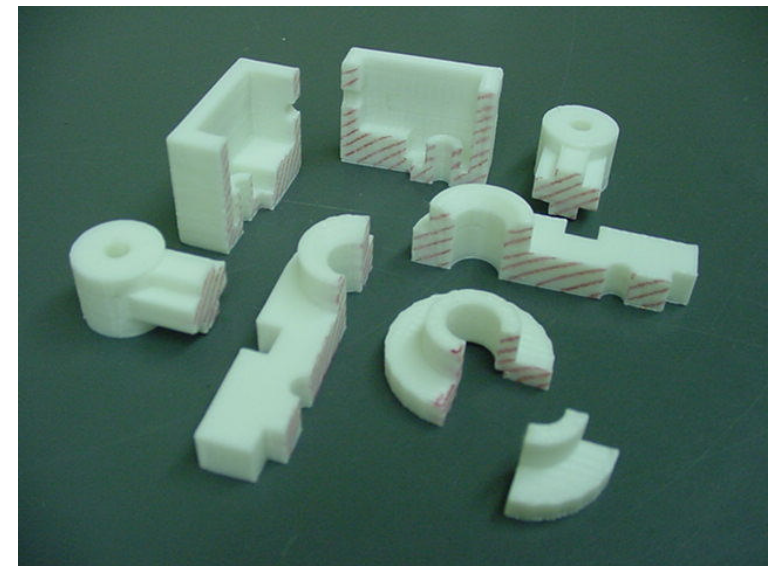

Figure 8: Workshop Section Models

The secondary (workshop) experiment was limited to students in GE103 who were not involved in the primary (in-class) experiment. Of these, students who did not do well on the PSVT:R pretest, which was 20 or less for the purposes of this study, were divided into two groups. Half were invited to attend a two-hour visualization workshop prior to the second written exam. Twenty workshop attendees made up the experimental group in this scenario, while eighteen students who did not attend the workshop made up the control group. Workshop topics included multiview, missing view, auxiliary view, and section view sketching problems. Two teaching assistants conducted the workshop and answered student questions. Students were provided with physical models associated with each of the ten paper and pencil exercises covered. Models were provided prior to the completion of each multiview drawing problem and after the completion (or partial completion) of the remaining topics. Physical models were used in the 
workshop in much the same way that they had been used by the experimental group of the primary (in-class) study. Proper techniques for solving each problem were also presented. The section view models used for the workshop are shown in Figure 8.

The experimental group for the second experiment had a mean of 17.47 with a standard deviation of 2.15 on the PSVT:R pre-test. Similarly, the control group had a mean of 18.20 with a standard deviation of 1.75. The data indicates that the experimental and control groups both had low visualization skills and were representative of individuals with this level of skill in the population under study; therefore, the data from this study should be valid for students of this skill level in the population.

Scores and times were tabulated for the PSVT:R pre and post-tests for both studies. The sketching section scores from written exam two were also compared in both studies. These problems, as was mentioned previously, were selected based on the high level of visual ability required for success as well as being a practical measure for success in GE103. The PSVT:R improvement and sketching subsection performance were used to determine the effectiveness of physical models in both studies.

\section{Results}

The benefit of physical models used in the primary, in-class, experiment is apparent when comparing the percentage of improvement of the experimental and control groups, as noted in Table 1. The experimental group achieved an additional three percent improvement over the control group as well as the all students group. However, it could be argued that more improvement in PSVT:R scores was expected in the experimental group since they had a lower PSVT:R pre-test average than both the control and all students groups. This data also demonstrated that the control group of the primary (in-class) experiment was representative of the general population in regards to PSVT:R improvement, both groups having about seven percent improvement. The experimental group's PSVT:R post-test average was also almost the same as for all students (25.85 versus 25.95 ), even though the experimental group's PSVT:R pretest average was lower. This shows that the use of physical models in the classroom helped to make up the initial PSVT:R deficit that the experimental group had when compared with the all students group.

Table 1: Primary (In-Class)/PSVT:R Average Scores

\begin{tabular}{|c|r|r|r|r|}
\hline Primary/PSVT:R Score & $\mathrm{n}$ & Pre-test & Post-test & \% Improvement \\
\hline Experimental & 26 & 23.54 & 25.85 & $9.80 \%$ \\
\hline Control & 27 & 25.26 & 26.96 & $6.74 \%$ \\
\hline All Students & 231 & 24.32 & 25.95 & $6.70 \%$ \\
\hline
\end{tabular}

As far as completion times for the PSVT:R, the expected decrease in completion times was noted for the all students group as well as the experimental and control groups in the primary, in-class, experiment. Notably, the experimental group had a greater percent reduction than both the control and the all students group, as presented in Table 2. 
Table 2: Primary (In-Class)/PSVT:R Average Completion Times

\begin{tabular}{|c|r|r|r|r|}
\hline Primary/PSVT:R Time & \multicolumn{1}{|c|}{$\mathrm{n}$} & Pre-test & Post-test & \% Reduction \\
\hline Experimental & 26 & $17: 59$ & $15: 30$ & $13.81 \%$ \\
\hline Control & 27 & $17: 42$ & $15: 28$ & $12.54 \%$ \\
\hline All Students & 231 & $17: 52$ & $15: 54$ & $11.03 \%$ \\
\hline
\end{tabular}

The results of the sketching portion of the second written exam for the primary (in-class) experiment are shown in Table 3. The control group performed slightly better than the experimental group did when considering this metric. These results were not entirely surprising, given the lower PSVT:R pre-test results of the experimental group (see Table 1). The experimental groups' average score was also higher than the all students' score, despite having lower PSVT:R pre-test scores. The percent correct values were calculated by dividing the average actual scores by the maximum possible score.

Table 3: Primary (In-Class)/Written Exam Two Sketching Scores

\begin{tabular}{|c|r|r|}
\hline Primary/Sketching Score & \multicolumn{1}{|c|}{$\mathrm{n}$} & $\%$ Correct \\
\hline Experimental & 26 & $80.13 \%$ \\
\hline Control & 27 & $81.40 \%$ \\
\hline All Students & 231 & $77.91 \%$ \\
\hline
\end{tabular}

The secondary (workshop) experiment followed the same trend as the primary (in-class) study with regard to percent improvement in PSVT:R scores. However, the improvement was more pronounced with the secondary (workshop) experiment, as seen in Figure 9. The value of physical models as used in the workshop was noticeable when comparing the percent improvement of the experimental and control groups, as noted in Table 4. The experimental group achieved an additional nine percent improvement over the control group. Both the experimental and the control groups improved more than the student population as a whole. However, it can be argued that more improvement in PSVT:R scores was expected in the experimental and control groups due to their lower PSVT:R pre-test average when compared to that of the all student group. Additionally, students who scored poorly on the PSVT:R pre-test might be more likely to put forth greater effort in both improving spatial ability and outdoing their PSVT:R pre-test scores.

Table 4: Secondary (Workshop)/PSVT:R Average Scores

\begin{tabular}{|c|r|r||r|r|}
\hline Secondary/PSVT:R Score & \multicolumn{1}{|c|}{$\mathrm{n}$} & Pre-test & Post-test & \% Improvement \\
\hline Experimental & 17 & 17.47 & 21.65 & $23.91 \%$ \\
\hline Control & 10 & 18.20 & 20.90 & $14.84 \%$ \\
\hline All Students & 231 & 24.32 & 25.95 & $6.70 \%$ \\
\hline
\end{tabular}




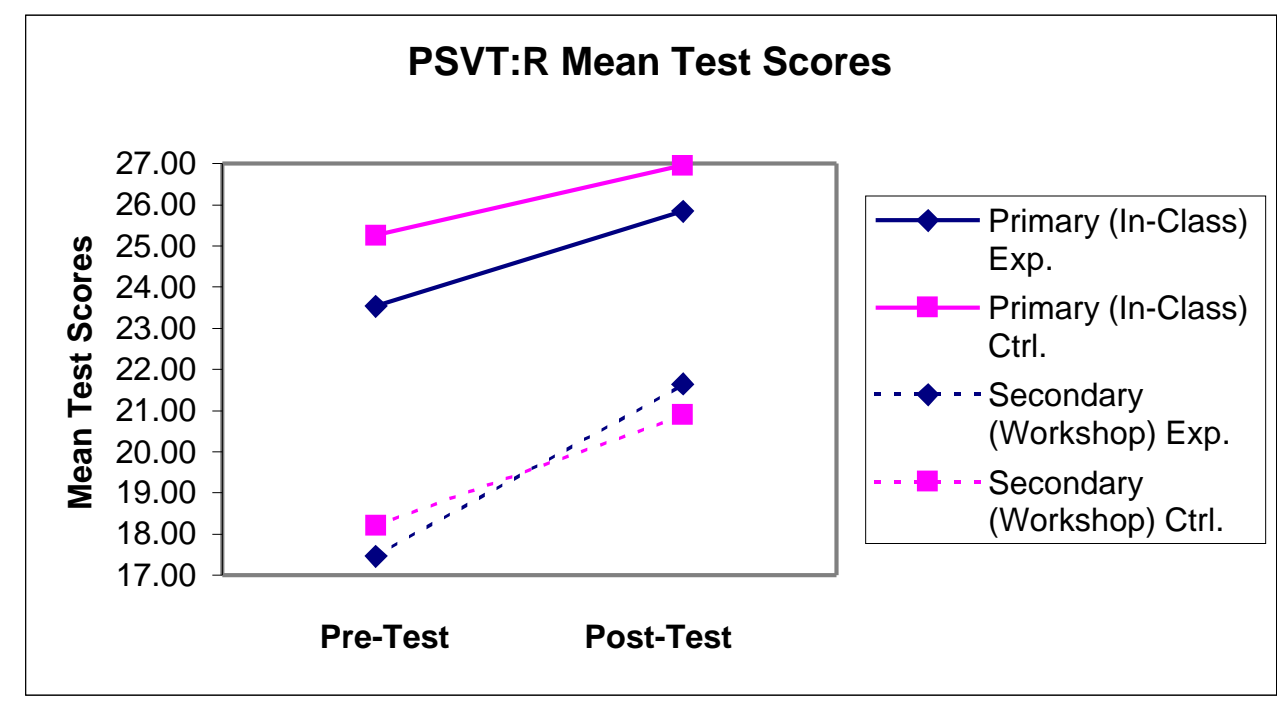

Figure 9: PSVT:R Mean Test Scores

The secondary, workshop, experiment did not demonstrate the same completion time trend as the primary, in-class, experiment, as seen in Figure 10. The experimental group of the secondary (workshop) experiment demonstrated considerably lower percent improvement over both the control group and all students as shown in Table 5. While improvement was still noted, the degree was less than expected. This may be due to greater time and effort put forth by these students, since they believed they could achieve higher scores than their counterparts (given that their counterparts did not have the benefit of the visualization workshop).

Table 5: Secondary (Workshop)/PSVT:R Average Completion Times

\begin{tabular}{|c|r|r|r|r|}
\hline Secondary/PSVT:R Time & \multicolumn{1}{|c|}{$\mathrm{n}$} & Pre-test & Post-test & \% Reduction \\
\hline Experimental & 17 & $18: 02$ & $17: 38$ & $2.17 \%$ \\
\hline Control & 10 & $18: 17$ & $15: 52$ & $13.25 \%$ \\
\hline All Students & 231 & $17: 52$ & $15: 54$ & $11.03 \%$ \\
\hline
\end{tabular}

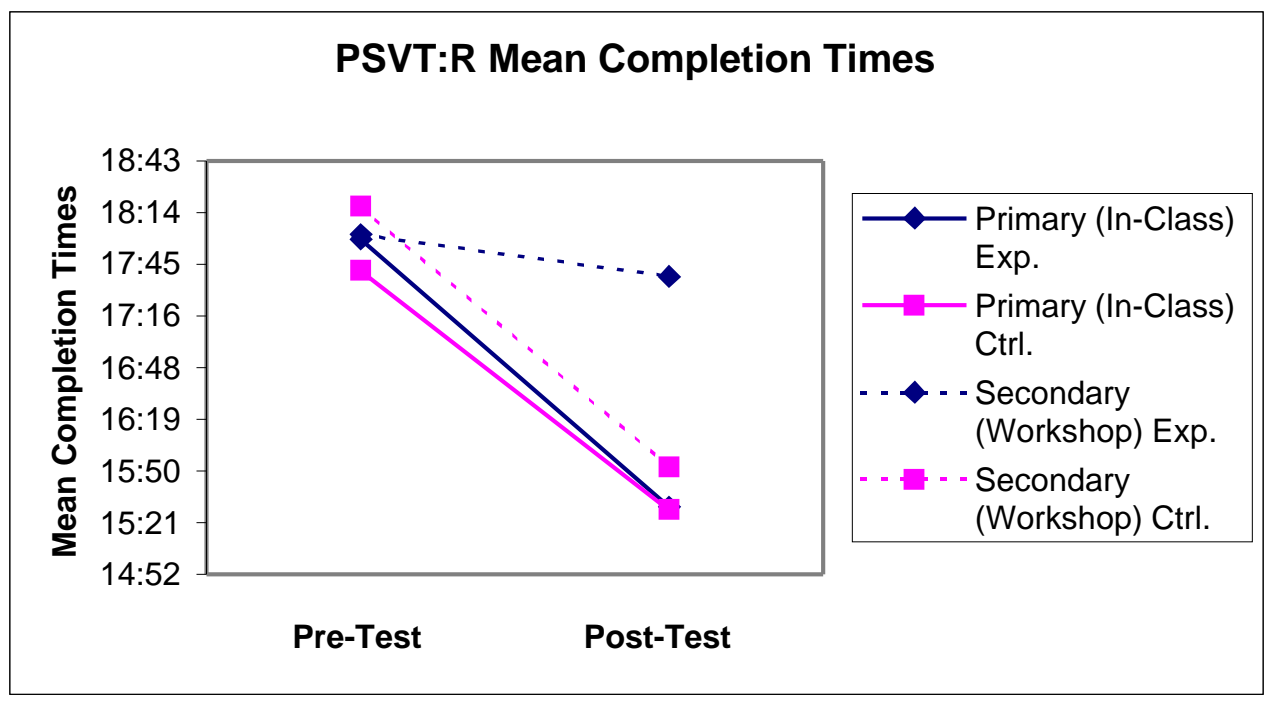

Figure 10: PSVT:R Mean Completion Times

Proceedings of the 2002 American Society for Engineering Education Annual Conference \& Exposition Copyright (C) 2002, American Society for Engineering Education 
Finally, the second written exam metric provided support for the greater effectiveness of physical models in a supplementary (workshop) environment over that of the primary (in-class) experiment. Table 6 shows that the experimental group outscored the control group by an additional three percent. However, it should be recalled that the primary, in-class, experiment control group outscored the experimental group (see Table 3). Returning to Table 6, both the experimental and control groups were outperformed by the all students group. It can certainly be argued that lower written exam two sketching scores were expected of the experimental and control groups, since their PSVT:R pre-test average was significantly lower than that of the all students group, as seen in Table 4.

Table 6: Secondary (Workshop)/Written Exam Two Sketching Scores

\begin{tabular}{|c|r|r|}
\hline Secondary/Sketching Score & $\mathrm{n}$ & $\%$ Correct \\
\hline Experimental & 17 & $73.04 \%$ \\
\hline Control & 10 & $70.42 \%$ \\
\hline All Students & 231 & $77.91 \%$ \\
\hline
\end{tabular}

\section{Conclusions and Recommendations}

Based on the improvement of PSVT:R scores and the sketching exam scores, rapid prototypes should be used when feasible for all 3-D assignments in both sketching and modeling labs. Qualitative information also supports the primary (in-class) study. For example, one student involved in the primary (in-class) study commented, "I got the gist of the assignments much better with the models." Likewise, another student in the same study explained, "The models were useful when I couldn't figure out what was going on." Finally, "They are very helpful in visualizing," commented another student. Teachers also provided positive feedback about the introduction of physical prototypes in their sections. A modeling lab teaching assistant commented, "They definitely made my job easier and my explanations shorter. For example, it was easier to use the model to explain the point of confusion than to draw a sketch and clear up the confusion. 3-D is always better than 2-D." Similarly, a sketching lab teaching assistant explained, "There was a noticeable difference in the length of an explanation with the models. When models were present students would attain understanding faster than if it were not there." Based on these findings, physical models should be used in the classroom. Since limited class time did not allow each model to be used to its fullest potential, providing fewer models is recommended in the future. These models should be provided with multiview, auxiliary view, section view, and missing view problem sets, as long as ample time is allotted for such use. If lab sections are structured around the use of physical models, such that more time is spent manipulating objects, they would likely have a greater effect on the primary (in-class) students' visualization abilities and greater improvement would be demonstrated.

The workshop showed more promise than the in-class experiment as far as both the PSVT:R and the sketching portion of the second written exam results are concerned. The workshop took less time and effort to prepare and run than the in-class experiment and provided better results. As such, workshops are planned for the Spring 2002 semester prior to both the first and second written exams. Workshop attendance will be suggested for students scoring poorly on the PSVT:R pre-test, but will be open to all students concerned with their visualization skills, regardless of their PSVT:R pre-test scores. To this end, one student who attended the workshop said, "You should do this more." It is believed that the expected increase in exam scores 
associated with the workshops will benefit student confidence with the material as well as student retention (in both the course and in engineering). As far as confidence is concerned, one workshop attendee remarked, "I think this session was helpful for me for the section views." Additionally, another student commented, "This really helped me. I'm really bad at visualizing these things and I think the models helped me the most." Qualitatively, the workshop also received more praise from the instructors than the in-class study. Teaching assistants stated, "I definitely think the students enjoyed the overall atmosphere of the session (workshop) and greatly benefited from it." Additionally, "Some students (attendees) only needed a word or pointer to genuinely see the answers after being stuck either with and without the models."

This study should be repeated in future semesters at UIUC with additional students and sections in order to further validate these findings. The researchers further recommend that other universities should implement similar studies to determine if the findings of this study hold true at other institutions. On that note, other visualization tests, such as the MRT, should be selected as both pre-test and post-test instruments for these experiments. Since no single visualization test claims to run the gamut of all visualization skills, additional visualization test results may further support or negate the statistical evidence produced here.

\section{Bibliography}

[1] Whiteacre, Matthew \& Wilson, James (2001). Using VRML to Assist Student Visualization in Freshman Engineering Classes. Paper presented at the 2001 ASEE Annual Conference Exposition.

[2] Miller, Craig L. (1992). Enhancing Visual Literacy of Engineering Students Through the Use of Real and Computer Generated Models. Engineering Design Graphics Journal, 56, (1), 27-38.

[3] Vander Wall, W. J. (1981). Increasing Understanding and Visualization Abilities using Three-Dimensional Models. Engineering Design Graphics Journal, 45, (2), 72-74.

[4] Rowe, C. E. (1945). Basic Models as an Effective Aid in Teaching Descriptive Geometry. Journal of Engineering Drawing, 9, (1), 7-9, 28.

[5] Orth, H. D. (1941). Establishing and Maintaining Standards of Excellence in Drawing. Journal of Engineering Drawing, 5, (1), 7-10.

[6] DeJong, Paul (1977). Improving Visualization, Fact or Fiction. Engineering Design Graphics Journal, 41, (1), 47-53.

[7] Vandenberg, S. G., and A. R. Kuse (1978). Mental Rotations, a Group Test of Three Dimensional Spatial Visualization. Perceptual and Motor Skills, 47, 599-604.

[8] Kelley, David S., Newcomer, Jeffrey L. \& McKell, Erik K. (2001). The Design Process, Ideation, and Computer-Aided Design. Paper presented at the 2001 ASEE Annual Conference Exposition.

Guay, R. B. (1977). Purdue Spatial Visualization Test: Rotations. West Lafayette, IN, Purdue Research Foundation. 